\title{
Strategi Pengembangan Birthday Organizer di Saka Kids Production Yogyakarta
}

\author{
Nurhana Azizia Latief \\ Program Pascasarjana Institut Seni Indonesia Yogyakarta, \\ Jalan Suryodiningratan 8, Yogyakarta \\ E-mail: hanaazizia8@gmail.com
}

\begin{abstract}
ABSTRAK
Penelitian ini bertujuan untuk mengidentifikasi strategi yang digunakan oleh organisasi Saka Kids Production Yogyakarta yang bergerak dalam bidang birthday organizer atau pengorganisasi acara ulang tahun. Saat ini, bisnis birthday organizer sedang berkembang di kota-kota besar di Indonesia, salah satunya Yogyakarta. Hal ini bermula dari banyaknya orangtua sibuk yang tidak sempat mengurus sendiri acara ulang tahun buah hati atau anggota keluarganya, sehingga menjatuhkan pilihan pada penyedia jasa birthday organizer. Organisasi yang menjadi objek penelitian ini menyediakan jasa perencanaan acara ulang tahun yang meliputi jasa badut sulap, badut karakter, dekorasi balon, dan paket ulang tahun. Banyaknya persaingan dalam bisnis ini membuat organisasi harus memperhatikan strategi agar dapat bertahan dalam pasar. Peneliti menggunakan metode penelitian kualitatif deskriptif dalam empat tahapan yaitu tahap pertama menentukan lingkup penelitian yang terdiri dari objek penelitian dan subjek penelitian. Tahap kedua melakukan teknik pengumpulan data melalui wawancara dengan key person/orang terpenting dalam organisasi. Tahap ketiga menentukan variabel yang mencakup faktor internal (kekuatan \& kelemahan) dan faktor eksternal (peluang \& ancaman). Tahap keempat melakukan analisis data dengan menggunakan analisis SWOT. Hasil penelitian menunjukkan bahwa strategi generik yang semestinya dijalankan oleh Saka Kids Production berdasarkan hasil analisis Matrik IE dan Kuadran SWOT adalah Ekspansion yang mendukung strategi efektivitas dan variasi strategi adalah Diversifikasi dan Intensif.
\end{abstract}

Kata kunci: strategi pengembangan, bisnis birthday planner, analisis SWOT

\section{Development Strategy for Birthday Organizer at Saka Kids Production Yogyakarta} ABSTRACT

This study aims to identify the Saka Kids Production Yogyakarta organization's strategies engaged in birthday organizers or birthday events organizers. Currently, the birthday organizer business is developing in big cities in Indonesia, Yogyakarta. This stems from the number of busy parents who do not have time to take care of their own baby's birthday event or family members, so the birthday organizer service provider's choice. The organization that is the object of this research provides birthday event planning services, which include the services of magic clowns, character clowns, balloon decorations, and birthday packages. The amount of competition in this business makes the organization pay attention to strategies to survive. Researchers used descriptive qualitative research methods with a case study approach in four stages, namely the first stage determining the scope of research consisting of research objects and research subjects. The second stage is conducting data collection techniques through interviews with key people / the organization's most influential people. The third stage determines internal factors (strengths \& weaknesses) and external factors (opportunities \& threats). The fourth step is analyzing data using SWOT analysis. The results showed that the generic strategy that should have been carried out by Saka Kids 
Production based on the results of the IE Matrix and SWOT Quadrant analysis was the expansion that supported the effectiveness strategy and the variations in the strategy were Diversification and Intensive.

Keywords: strategy development, birthday planner business, SWOT analysis

\section{PENDAHULUAN}

Tingginya pertumbuhan ekonomi dan globalisasi saat ini membuat manusia dituntut untuk berpikir kritis dan kreatif dalam mengembangkan berbagai usaha dan bisnis untuk dapat bertahan dalam persaingan maupun sekedar mencukupi kebutuhan, baik kebutuhan fisik maupun rohani. Hal ini ditunjukkan dengan semakin banyak bermunculan bisnis yang mengikuti perkembangan zaman, tren, dan juga gaya hidup orang-orang masa kini. Pelaku bisnis membaca berbagai peluang yang kemudian diimplementasikan dengan wujud baru atau ide bisnis lama yang dikemas ulang dengan sentuhan inovasi dan kreativitas baru. Namun, terkadang munculnya bisnis baru tersebut tidak didasari dengan strategi yang tepat sehingga sulit bertahan dalam pasar.

Tuntutan ekonomi dan kebutuhan membuat banyak orang memilih untuk bekerja, baik pria maupun wanita. Banyak orang yang disibukkan dengan segudang pekerjaan dan aktivitas di luar rumah, berbeda dengan kondisi orang-orang pada zaman dahulu. Pada akhirnya, banyak orang memilih untuk menggunakan jasa orang lain seperti membersihkan rumah, mencuci kendaraan, atau mengurus pekerjaan lain yang tidak bisa dilakukan sendiri sebagai cara praktis untuk menyelesaikan pekerjaan tersebut. Hal ini yang kemudian menjadi gagasan atau ide untuk memanfaatkan peluang dalam menjalankan bisnis di bidang pengorganisasian pesta ulang tahun anak agar memudahkan orangtua sibuk yang ingin merayakan ulang tahun buah hati. Kemudian terbentuk sebuah organisasi bisnis yang diberi nama Saka Kids Production Yogyakarta dengan pemilik usaha Bapak Dhimas.

Saka Kids Production Yogyakarta didirikan pada 13 Maret 2016 oleh Bapak Dhimas Mujiburrohman. Bermula dari kegiatan Bapak Dhimas yang sering menghibur pengunjung taman bermain Kids Fun Yogyakarta, kemudian Bapak Dhimas berkeinginan untuk menekuni profesi sebagai badut yang memiliki keterampilan memainkan berbagai macam jenis sulap. Keterampilannya tersebut dijadikan sebagai modal untuk mendirikan usaha sendiri dalam bidang hiburan anak-anak, khususnya pada acara perayaan ulang tahun.

Setelah beberapa kali mengisi acara ulang tahun, kemudian Bapak Dhimas berpikir untuk menambah keahliannya dalam merangkai atau mendekorasi balon sebagai pendukung kemeriahan pesta. Hingga saat ini, Saka Kids Production Yogyakarta sudah menangani berbagai keperluan pesta dari proses perencanaan 
hingga pelaksanaan yang meliputi jasa badut sulap dan badut karakter, dekorasi balon untuk berbagai macam acara, hingga paket ulang tahun yang dapat disesuaikan dengan keinginan konsumen. Usaha ini telah berjalan selama kurang lebih empat tahun dan telah memiliki tiga orang karyawan dengan tugasnya masingmasing. Organisasi bisnis yang bergerak dalam perencanaan ulang tahun di Yogyakarta semakin hari semakin bertambah, sehingga muncul kekhawatiran pengelola dalam pengembangan usaha agar tetap bertahan dalam persaingan pasar, maka diperlukan strategi yang tepat dalam pengelolaan Saka Kids Production Yogyakarta sebagai acuan pengembangan usaha tersebut.

\section{METODE}

Penelitian ini dilakukan untuk mengetahui strategi yang tepat untuk pengembangan organisasi Saka Kids Production Yogyakarta sehingga organisasi tersebut dapat bertahan dalam pasar bisnis dan dapat bersaing dengan organisasi yang bergerak dalam bidang serupa. Penelitian menggunakan metode deskriptif kualitatif dan analisis data menggunakan analisis SWOT. Dari hasil pengamatan dan penelitian yang dilakukan ini hasilnya kemudian akan diolah menggunakan beberapa alat, yaitu matriks IE dan kuadran SWOT, kemudian laporan hasil penelitian ini akan disajikan dalam bentuk tertulis. Adapun tahapan dalam penelitian adalah sebagai berikut:

1. Objek Penelitian

Objek penelitian adalah Saka Kids Production Yogyakarta yang beralamatkan di Temuwuh Kidul RT 03/RW 31 Balecatur, Gamping, Sleman, Daerah Istimewa Yogyakarta.

2. Subjek Penelitian

Subjek penelitian adalah pengelola inti dari Saka Kids Production Yogyakarta, terdiri dari dua orang yakni Dhimas Mujiburrohman sebagai pemilik dan Bachtiar Firgiawan sebagai administrasi dan promosi.

3. Teknik Pengumpulan Data

Teknik pengumpulan data dengan wawancara terhadap pengelola inti Saka Kids Production Yogyakarta dan kuesioner yang merupakan instrumen penelitian yang digunakan melalui daftar pertanyaan yang diisi responden (key person) yang kemudian digunakan untuk pengukuran bobot dan rating. Untuk kelengkapan data dilakukan juga dokumentasi, yakni pengumpulan dan pengolahan serta penyimpanan informasi sebagai pendukung penelitian ini.

4. Variabel Penelitian

Penelitian ini dilakukan melalui dua faktor, yaitu faktor internal (kekuatan dan kelemahan) serta faktor eksternal (peluang dan ancaman). 


\section{HASIL DAN PEMBAHASAN}

\section{A. Potensi Bisnis Birthday Organizer}

Di era globalisasi dan digital saat ini, banyak sekali orang yang memilih menjalankan usaha di bidang jasa birthday organizer atau yang hampir serupa dengan party planner. Menggunakan jasa birthday organizer merupakan cara praktis untuk menghemat biaya dan memastikan secara detail kebutuhan pesta, serta mengurus keseluruhan acara. Tidak hanya itu, menyewa jasa birthday organizer dapat menjadi aset yang sangat berharga untuk kelancaran sebuah acara pesta ulang tahun yang menarik. Pemanfaatan media sosial sebagai sarana promosi membuat proses pemasaran usaha semakin mudah. Beberapa keuntungan dari penggunaan jasa birthday organizer antara lain adalah:

1) Anggaran terkendali

Birthday organizer dapat membantu melacak harga secara keseluruhan dan menjadi konsultan pesta ulang tahun agar anggaran dapat terkendali.

2) Mencakup detail

Detail desain dekorasi pesta serta penyusunan acara menjadi lebih terkonsep sehingga lebih memudahkan konsumen dalam merayakan pesta ulang tahun.

3) Skill Manajemen dan Negosiasi

Dalam menjalankan bisnis birthday organizer, pelaku bisnis dituntut untuk memiliki skill manajemen dan negosiasi yang mumpuni untuk dapat menghadapi persaingan yang kian tinggi.

4) Tema dan Tempat

Tema dan tempat dapat disesuaikan keinginan serta konsep yang diangkat. Hal tersebut berkaitan dengan anggaran konsumen dan desain keseluruhan acara.

5) Fleksibilitas

Menyewa jasa birthday organizer bersifat fleksibel atau dinamis. Konsep serta detail acara tidak selalu berdasarkan rancangan pihak organizer, tetapi dapat disesuaikan dengan keinginan dan anggaran pihak konsumen, sehingga penggunaan jasa birthday organizer cukup memberi keuntungan, baik waktu, tenaga, serta biaya.

6) Mengurangi Stres

Penggunaan jasa birthday organizer dapat mengurangi stres tuan rumah atau penyelenggara pesta karena segala keperluan telah diurus dengan baik dan rinci.

7) Menghemat Waktu

Bagi orang yang sibuk bekerja, menggunakan jasa birthday organizer merupakan pilihan yang tepat karena lebih menghemat waktu.

8) Saran Acara

Selain dekorasi pesta, birthday organizer juga memberi masukan dan membantu dalam merancang keseluruhan detail acara pesta ulang tahun. 
Dengan berbagai keuntungan tersebut, bisnis birthday organizer menjadi bisnis yang banyak ditekuni dan digeluti oleh banyak orang karena dipandang memiliki potensi cukup besar dalam pasar bisnis lima hingga sepuluh tahun ke depan. Kreativitas dan kapabilitas dalam mendesain pesta harus selalu diasah dan terus ditingkatkan (update) agar dapat bertahan dalam persaingan pasar dan sebagai modal dalam berkompetisi dengan organisasi bisnis yang serupa. Potensi dari bisnis birthday organizer yang dijalankan oleh Saka Kids Production Yogyakarta yaitu:

1. Memiliki pemain badut yang lengkap sehingga dapat memenuhi permintaan konsumen.

2. Melayani ketersediaan jenis barang atau kebutuhan ulang tahun, baik dari dekorasi tempat, konsumsi, maupun acara, sehingga memudahkan orang yang ingin merayakan pesta ulang tahun dengan meriah.

3. Memberikan hiburan yang edukatif melalui sulap dan permainan sehingga bersifat ramah anak.

4. Memiliki desain dekorasi ulang tahun yang variatif serta terus berkembang mengikuti tren dan selera pasar sehingga mampu memberikan hasil terbaik.

\section{B. Strategi Pengembangan Bisnis Saka Kids Production}

Hasil analisis SWOT menunjukkan bahwa posisi usaha Saka Kids Production melalui Matriks IE berada pada Growth and Build (tumbuh dan bina) karena berada pada posisi II. Strategi yang cocok adalah intensif (penetrasi pasar, pengembangan pasar, dan pengembangan produk) atau integrasi (integrasi ke belakang, integrasi ke depan, dan integrasi horizontal).

\section{Kuadran Analisis SWOT}

Untuk kuadran analisis SWOT usaha Saka Kids Production dihitung berdasarkan berikut:

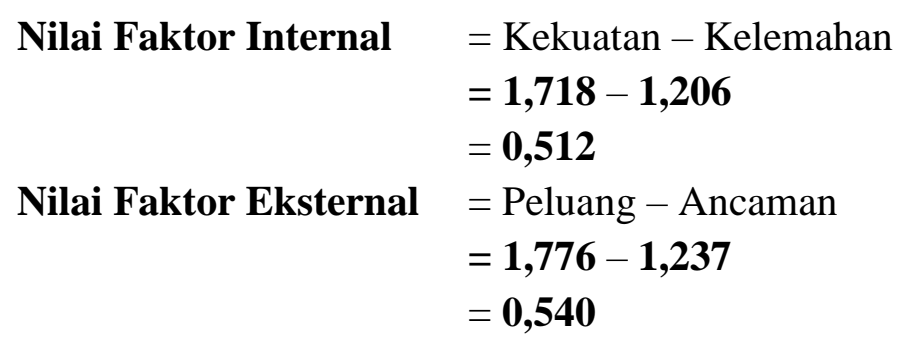




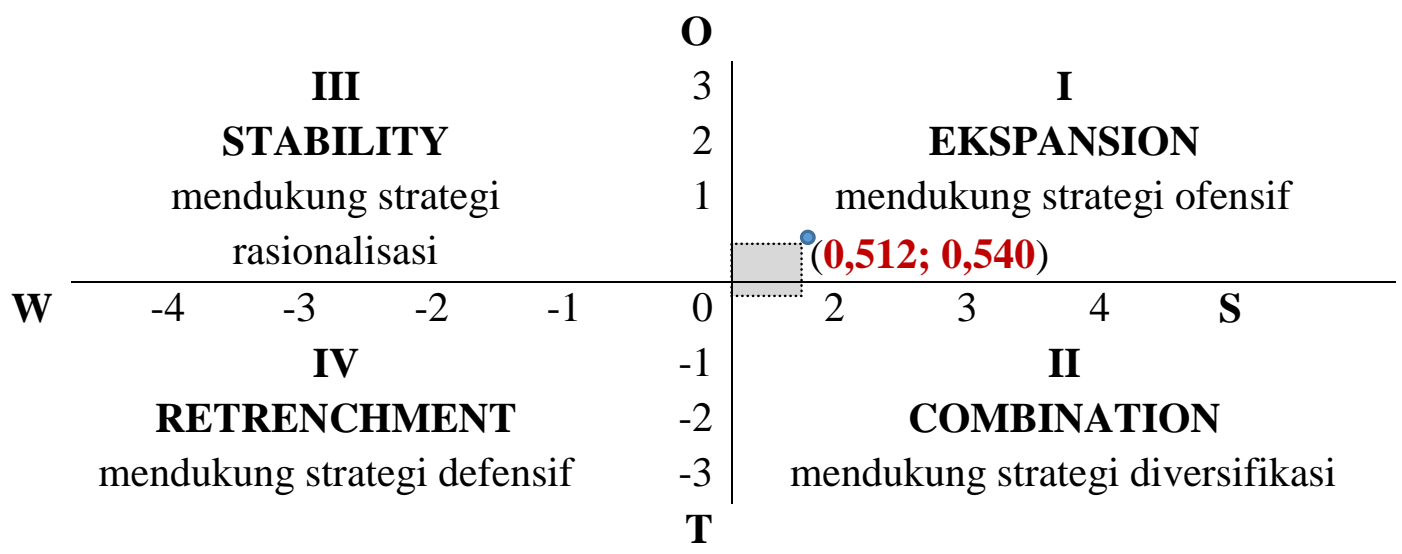

Gambar 1. Kuadran analisis SWOT usaha Saka Kids Production Sumber: Data survei peneliti, 2018

Kuadran analisis SWOT usaha Saka Kids Production menunjukkan posisinya berada pada kuadran I sehingga diperlukan pemilihan strategi yang berupa penggunaan setiap kekuatan untuk menghadapi setiap ancaman dengan menciptakan diversifikasi untuk menciptakan peluang. Selanjutnya adalah perumusan strategi melalui matriks SWOT yang diperoleh dengan memasangkan faktor-faktor eksternal dengan internal. Dalam matriks SWOT diperlihatkan kesesuaian antara kekuatan, kelemahan, peluang, dan ancaman.

\section{Matriks SWOT}

Matriks SWOT diperoleh dengan memasangkan faktor-faktor eksternal dengan internal. Dalam matriks SWOT diperlihatkan kesesuaian antara kekuatan, kelemahan, peluang, dan ancaman seperti terlihat pada tabel berikut.

Tabel 1. Alternatif strategi dalam matriks SWOT

Sumber: Matriks SWOT Rangkuti (2006)

\begin{tabular}{|c|c|c|}
\hline Eksternal & $\begin{array}{l}\text { Strength }(S) \\
\text { *Faktor Kekuatan }\end{array}$ & $\begin{array}{l}\text { Weakness }(W) \\
\text { *Faktor Kelemahan }\end{array}$ \\
\hline Opportunities $(O)$ & Strategi SO & Strategi WO \\
\hline *Faktor Peluang & $\begin{array}{l}\text { Ciptakan strategi yang } \\
\text { menggunakan kekuatan untuk } \\
\text { memanfaatkan peluang. }\end{array}$ & $\begin{array}{l}\text { Ciptakan strategi yang } \\
\text { meminimalkan kelemahan } \\
\text { untuk memanfaatkan } \\
\text { peluang. }\end{array}$ \\
\hline Threaths $(T)$ & Strategi ST & Strategi TW \\
\hline *Faktor Ancaman & $\begin{array}{l}\text { Ciptakan strategi yang } \\
\text { menggunakan kekuatan untuk } \\
\text { mengatasi ancaman. }\end{array}$ & $\begin{array}{l}\text { Ciptakan strategi yang } \\
\text { meminimalkan kelemahan } \\
\text { dan menghindari ancaman. }\end{array}$ \\
\hline
\end{tabular}


Berdasarkan hasil kuadran analisis SWOT, usaha Saka Kids Production menunjukkan posisinya berada pada kuadran I yaitu Ekspansion mendukung strategi efektivitas (penambahan produk, pasar, dan fungsi-fungsi perusahaan). Selanjutnya perlu dirumuskan alternatif-alternatif strategi menggunakan matrik SWOT untuk mendukung keputusan dari hasil analisis kuadran SWOT. Perumusan strategi-strategi melalui matriks SWOT adalah sebagai berikut.

Tabel 2 Alternatif strategi usaha Saka Kids Production dalam matriks SWOT Sumber: Data survei peneliti, 2018

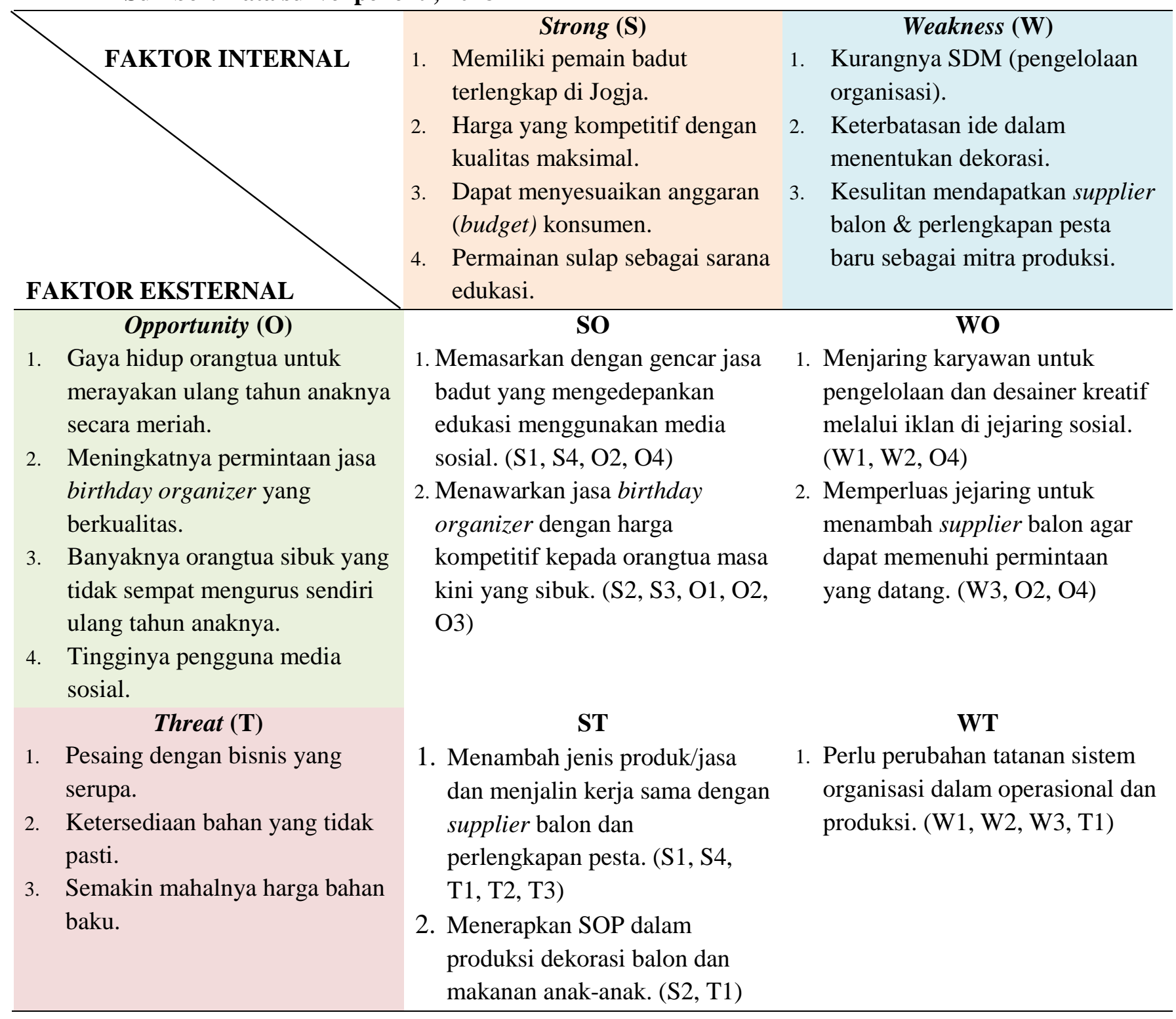




\section{Tahapan Keputusan}

Hasil Matriks SWOT memberikan beberapa alternatif strategi, yaitu:

SO : 1. Memasarkan dengan gencar jasa badut yang mengedepankan edukasi menggunakan media sosial.

2. Menawarkan jasa birthday organizer dengan harga kompetitif kepada orangtua masa kini yang sibuk.

WO : 1. Menjaring karyawan untuk pengelolaan dan desainer kreatif melalui iklan di jejaring sosial.

2. Memperluas jejaring untuk menambah supplier balon agar dapat memenuhi permintaan yang datang.

ST : 1. Menambah jenis produk/jasa dan menjalin kerja sama dengan supplier balon dan perlengkapan pesta.

2. Menerapkan SOP dalam produksi dekorasi balon dan makanan anak-anak.

WT : 1. Perlu perubahan tatanan sistem organisasi dalam operasional dan produksi.

- Tahap keputusan berdasarkan Matriks IE.

Posisi usaha Saka Kids Production melalui Matriks IE menunjukkan Growth and Build (tumbuh dan bina) karena berada pada posisi II. Strategi yang cocok adalah intensif (penetrasi pasar, pengembangan pasar, dan pengembangan produk).

○) Intensif.

- Penetrasi Pasar: memasarkan dengan gencar jasa birthday organizer dan badut sulap edukatif dengan menggunakan media sosial.

- Pengembangan Pasar: menambah dan memperluas jaringan kerja sama dengan supplier maupun manajer-manajer perusahaan untuk membuka pangsa pasar baru.

- Pengembangan Produk: menambah jenis produk/jasa baru yang inovatif.

- Tahap keputusan berdasarkan Kuadran Analisis SWOT.

Kuadran Analisis SWOT Usaha Saka Kids Production menunjukkan posisinya berada pada kuadran I Ekspansion sehingga diperlukan pemilihan strategi yang berupa penggunaan setiap kekuatan untuk menghadapi setiap ancaman. Posisi tersebut mengarah pada strategi ST yaitu:

1. Menambah jenis produk/jasa dan menjalin kerja sama dengan supplier balon dan perlengkapan pesta.

2. Menerapkan SOP dalam produksi dekorasi balon dan makanan anak-anak. Strategi generik yang diterapkan oleh usaha Saka Kids Production saat ini adalah Fokus. Strategi Fokus menghindari konfrontasi langsung dengan para pesaingnya, konsentrasi pada pangsa pasar yang kecil (niches). 
Strategi: a) Overall cost leadership (fokus ke pesaing daripada ke pelanggan, harga jual murah/bisa dilakukan karena mengusahakan biaya produksi murah).

b) Differentiation (melayani pangsa pasar yang kecil sehingga lebih baik dari para pesaing).

Hal ini terbukti dengan proses bisnis yang dilakukan oleh Bapak Dhimas yaitu memberikan atau menyediakan jasa badut, paket ulang tahun, dan dekorasi balon dengan harga yang cukup bersaing namun tetap berkualitas. Pak Dhimas membaca peluang bahwa keinginan kebanyakan konsumen adalah dapat menyewa jasa badut, paket ulang tahun, dan dekorasi balon yang bagus namun dengan harga yang relatif murah.

Variasi strategi yang diterapkan oleh Saka Kids Production adalah Pengembangan Produk (perbaiki dan kembangkan produk yang ada) dan Diversifikasi Konsentrik (menambah produk baru yang saling berhubungan untuk pasar yang sama). Pada usaha Saka Kids Production yang dijalankan oleh Bapak Dhimas ini awalnya hanya menerima permintaan jasa badut untuk menghibur dalam acara ulang tahun anak-anak, namun kemudian Bapak Dhimas belajar untuk membuat dekorasi balon dan hingga saat ini berusaha untuk menambah produk sebagai paket lengkap acara ulang tahun seperti MC formal/casual, magic for kids, sweet corner, piñata, hiburan organ tunggal, sound system, foto, video, snack ultah, goody bag/souvenir, bento, undangan \& topi ultah, dan kue tar.

Berdasarkan hasil Analisis Matriks IE dan Kuadran SWOT, maka strategi pengembangan yang sebaiknya diterapkan oleh organisasi Saka Kids Production Yogyakarta adalah:

1. Strategi generik yaitu Ekspansion yang mendukung strategi efektivitas.

Dilihat dari hasil analisis matriks IE, posisi usaha Saka Kids Production menunjukkan Growth and Build (tumbuh dan bina) karena berada pada posisi II. Variasi strategi yang cocok adalah Intensif atau Integrasi. Sedangkan menurut hasil kuadran SWOT posisi usahanya berada pada kuadran I yaitu Strategi Generik Ekspansion. Oleh karena itu, dalam usaha ini strategi generik yang akan digunakan adalah Ekspansion. Untuk variasi strategi yang akan digunakan adalah diversifikasi (variasi strategi kuadran SWOT) dan intensif (variasi strategi dari matriks IE).

a. Variasi Strategi yang digunakan adalah diversifikasi dan intensif yaitu sebagai berikut:

1. Diversifikasi: Diversifikasi Kosentrik yaitu menambah produk baru yang saling berhubungan untuk pasar yang sama.

2. Intensif:

a) Penetrasi Pasar yaitu memasarkan dengan gencar produk/jasa badut, paket ulang tahun, dan dekorasi balon dengan menggunakan media sosial. 
b) Pengembangan Pasar: menambah dan memperluas jaringan kerja sama dengan supplier dan manajer-manajer perusahaan untuk membuka pangsa pasar baru.

c) Pengembangan Produk: menambah produk/jasa yang inovatif dan berkualitas.

b. Strategi generik \& variasi strategi yang akan datang (3-5 tahun).

1) Strategi generik

Untuk tiga sampai lima tahun mendatang, strategi generik sebenarnya sangat susah ditentukan tanpa studi kelayakan bisnis. Sangat penting untuk melihat perkembangan usaha sejauhmana dalam dua tahun ke depan ini. Jika strategi yang dihasilkan berdasarkan analisis SWOT diterapkan dan berjalan dengan baik maka selanjutnya strategi generik yang bisa digunakan adalah fokus konsumen. Fokus konsumen dalam arti ini tidak perlu lagi gencar untuk menambah produk dan jaringan kerja sama untuk supplier, karena sudah pasti usaha Saka Kids Production ini sudah memiliki banyak jenis produk dan jaringan kerja sama. Maka, untuk waktu tiga sampai lima tahun mendatang tersebut usaha Saka Kids Production perlu fokus konsumen untuk menjaga hubungan usaha dapat berjalan dengan baik dan lancar.

2) Variasi Strategi

Variasi Strategi yang dapat diterapkan untuk tiga sampai lima tahun mendatang adalah sebagai berikut (dilihat dari Strategi Generik Fokus Konsumen).

- Pengembangan pasar (market development) yaitu meningkatkan pangsa pasar dengan membuat penawaran paket ulang tahun yang dibuat secara bertingkat dari biasa, menengah, dan atas. Dengan demikian, konsumen tidak hanya dari konsumen rumahan, namun bisa merambah pada konsumen kelas atas yang biasa merayakan pesta ulang tahun anaknya di hotel ataupun resto mewah.

- Pengembangan produk yaitu meningkatkan kualitas produk/jasa dan menjaga stabilitas keberlanjutan produk/jasa itu sendiri (jangan sampai produk/jasa tidak tersedia saat terjadi permintaan).

\section{KESIMPULAN}

Tujuan utama pada penelitian ini adalah untuk mengembangkan strategi usaha Saka Kids Production Yogyakarta yang sedang berada pada tahap awal menjalankan bisnis pengorganisasi acara ulang tahun. Berdasarkan Analisis Matriks IE (Internal-Eksternal) dan Kuadran SWOT maka dapat disimpulkan strategi usaha untuk Saka Kids Production sebagai berikut:

a. Startegi Generik: Ekspansi (Ekspansion)

b. Variasi Strategi: 
1. Diversifikasi Konsentrik yaitu menambah produk baru yang saling berhubungan untuk pasar yang sama.

2. Penetrasi Pasar: memasarkan dengan gencar produk/jasa badut, paket ulang tahun, dan dekorasi balon dengan menggunakan media sosial.

3. Pengembangan Pasar: menambah dan memperluas jaringan kerja sama dengan supplier dan manajer-manajer perusahaan untuk membuka pangsa pasar baru.

c. Pengembangan Produk: menambah produk/jasa yang inovatif dan berkualitas.

\section{Saran}

1. SWOT dalam penelitian ini tidak semuanya mengandung empat pilar utama yaitu produksi/operasi, SDM, Pemasaran, dan Keuangan. Disarankan untuk ke depannya setiap unsur dari kekuatan, kelemahan, peluang, dan ancaman mengandung analisis dari empat pilar tersebut.

2. Untuk penyusunan strategi berikutnya dapat menggunakan analisis strategi yang berbeda seperti BCG, Five Porter, dll.

\section{KEPUSTAKAAN}

Alimudin, A. (2015). Strategi Pengembangan Minat Wirausaha Melalui Proses Pembelajaran. E-Jurnal Manajemen Kinerja, 1(1).

Arfiyanto, Dedy; Faris, R. I. (2016). Strategi Event Organizer (EO) PT. SAFIS KARYA SENTOSA Pamekasan dalam Menggerakkan Bisnis Industri Kreatif di Madura. Eco-Entrepreneur-Universitas Trunojoyo, 2(2).

Bahren; Hidayat, Herry Nur; Sudarmoko; Setyaka, V. (2014). Industri Kreatif Berbasis Potensi Seni Dan Sosial Budaya di Sumatera Barat. Jurnal Ekspresi Seni, 16(1).

Barringer, Richard, E. al. (n.d.). The Creative Economy in Maine: Measurement \& Analysis", The Southern Maine Review. University of Southern Maine.

Christopherson, S. (2004). Creative Economy Strategies for Small and Medium Size Cities: Options for New York State. Quality Communities Marketing and Economics Workshop. Albany, New York.

David, F. R. (2010). Manajemen Strategis. Jakarta: Salemba Empat.

Fatimah, F. N. D. (2017). Teknik Analisis SWOT. Jakarta: Anak Hebat Indonesia.

Ferdiansyah. (2016). Pengembangan Bisnis TGIF Organizer dalam Meningkatkan Market Share. Jurnal Bisnis Dan Manajemen, 52(11), 270-297.

Hamid, Suandi; Edy; Susilo, Y. S. (2011). Strategi Pengembangan Usaha Mikro Kecil dan Menengah di Provinsi Daerah Istimewa Yogyakarta. Jurnal Ekonomi Pembangunan, 12(1), 45-55.

Moleong, J. L. (2010). Metodologi Penelitian Kualitatif. Bandung: PT Remaja Rosdakarya.

Muhandri, T. (2002). Strategi Penciptaan Wirausaha (Pengusaha) Kecil Menengah Yang Tangguh. Bogor: Falsafah Sain IPB. 
Nurcahyati; Ratnawati, A. T. (2016). Strategi Pengembangan Industri Kreatif Sebagai Penggerak Destinasi Pariwisata di Kabupaten Semarang. Prosiding Seminar Nasional Multi Disiplin Ilmu \& Call for Papers Unisbank (Sendi U) Ke-2 Tahun 2016.

Pickton, David W.; and Wright, S. (1998). What's SWOT in Strategic Analysis? In Strategic Change, 7 (1998) (pp. 101-109). United States: John Wiley \& Sons, Ltd.

Prasojo, L. D. (2018). Manajemen Strategi. Yogyakarta: UNY Press.

Prayudi, Dicki; Yulistria, R. (2020). Penggunaan Matriks SWOT dan Metode QSPM pada Strategi Pemasaran Jasa Wedding Organizer: Studi Kasus pada UMKM Gosimplywedding Sukabumi. Jurnal Maksipreneur, 9(2), 225 241.

Rangkuti, F. (2016). Analisis SWOT: Teknis Membedah Kasus Bisnis Cara Perhitungan Bobot, Rating dan OCAL. Jakarta: PT Gramedia Pustaka Utama.

Riyanto, J. (2018). Pengembangan Strategi Pengelolaan Sanggar Srengenge Mas Bantul. Jurnal Tata Kelola Seni, 4(1), 49-62. https://doi.org/https://doi.org/10.24821/jtks.v4i1.3082

Rochaeni, A. (2008). Strategi Pengembangan Sumber Daya Manusia dalam Era Kompetisi. Jurnal Manajemen \& Sistem Informasi UPI, 6(12).

Utaminingsih, A. (2016). Pengaruh Orientasi Pasar, Inovasi, dan Kreativitas Strategi Pemasaran terhadap Kinerja Pemasaran pada UKM Kerajinan Rotan di Desa Teluk Wetan, Welahan, Jepara. Media Ekonomi Dan Manajemen, 31(2).

Wijayanto, H. (2018). Strategi Pengembangan Surabaya Art Event (SAE). Melayu Arts and Performance Journal, 1(2).

\section{Informan}

Dhimas Mujiburrohman, 35 tahun. (2020). Pemilik dan pendiri Saka Kids Production Yogyakarta, tinggal di Desa Sinduadi Kecamatan Mlati Kabupaten Sleman Daerah Istimewa Yogyakarta

\section{Webtografi}

Amelia; Lestari, R. B. M. (2016). Bussiness Plan Party Planner Unique Jurusan Ilmu Ekonomi Manajemen, STIE MDP Palembang. Retrieved from http://eprints.mdp.ac.id/2052/1/Jurnal-2013200011.pdf 